\title{
La perpetuación de la Revolución de 1910
}

\section{Britney Cox}

Las revoluciones que han ocurrido en la historia han servido como la fundación de tantas civilizaciones. Asimismo, otra perspectiva del concepto de la Revolución es la culminación de sucesos que han ayudado a desarrollar la música, la cultura, el estilo de vida y especialmente la percepción del cambio por parte de la gente. Todos los productos culturales que analizamos a continuación son representaciones icónicas de la evolución de la Revolución de 1910 e ilustran la evolución de los mexicanos frente al mundo.

Por décadas, para líderes, movimientos políticos, artistas y directores, el concepto de Revolución ha permanecido relevante y vivo, y sirve como una fundación de la identidad de los mexicanos. La Revolución de 1910 ha influido en tantas generaciones de mexicanos, ha evolucionado la perspectiva de los mexicanos frente al mundo y específicamente ha dado vida al concepto de "lo mexicano" en las obras de arte, el cine y la filosofía de personas prominentes.

Uno de los mejores ejemplos de artistas influyentes es Frida Kahlo, quien usaba sus obras para expresar la verdad de las luchas de los mexicanos y la autenticidad de sus luchas personales y emocionales.

La Fridal de Frida (29 de septiembre de 2016) fue una obra teatro patrocinada por el Center for Mexican American Studies de UTA. Aspectos de la Revolución y símbolos de la cultura decoraron el escenario. La obra Las dos Fridas tomó formas reales y humanas. El contraste entre las Fridas es un espejo que reflexiona sobre los diferentes deseos: dar a luz a un niño y dar a luz a la Revolución. Esos deseos de Frida representan los mismos deseos y las mismas luchas de los mexicanos en los tiempos anteriores de la Revolución de 1910. Básicamente, el teatro fue una exposición de las artes influyentes de Kahlo, y cómo su vida y obra, en esencia, fueron una reflexión sobre la Revolución mexicana y perpetuaron este concepto para una audiencia moderna.

Además, en el ámbito del cine, Emilio Fernández y Gabriel Figueroa, una combinación icónica, crearon películas para que el mundo reconociera sus arte como uno de "un mexicano para los mexicanos", lo cual consiguieron debido a la falta de reconocimiento inicial de los mexicanos al cine del país. Fernández y Figueroa querían eliminar la influencia de Hollywood en su cine para educar a los mexicanos sobre "lo mexicano".

En la película Flor Silvestre (1943), en las primeras escenas, la cámara se enfoca en la tierra en su mayoría. La tierra es un símbolo importante para el cine porque es una representación de cómo la tierra ha 
sido siempre importante para la identidad y es una representación importante para los indígenas del área.

Finalmente, la filosofía de la Revolución es evidente cuando revisitamos los materiales históricos y artísticos desde 1910. Los productos culturales sobre la Revolución demuestran que ésta es un concepto o movimiento que es todavía importante para cada mexicano pasado y moderno. La sensación de orgullo, identidad y sentido de pertenencia son algunos de los valores en la base de muchas revoluciones. Es evidente que la Revolución mexicana sigue siendo una influencia debido a sus fuertes valores. 


\section{Bibliografía}

Teatro Flor Candela. "Rosebud Auditorium". Center for Mexican American Studies at UT Arlington. Web. 18 Oct. 2016.

Motian-Meadows, Mary. "Kahlo as Artist, Woman, Rebel”. Solidarity. Web. 18 Oct. 2016. 